\title{
First interactive simulations of cirrus clouds formed by homogeneous freezing in the ECHAM general circulation model
}

\author{
U. Lohmann \\ Department of Physics and Atmospheric Science, Dalhousie University, Halifax, \\ Nova Scotia, Canada
}

\author{
B. Kärcher \\ Deutsches Zentrum für Luft- und Raumfahrt, Institut für Physik der Atmosphäre, Wessling, Germany
}

Received 24 April 2001; revised 11 September 2001; accepted 8 October 2001; published 31 May 2002.

[1] A physically based parameterization for the nucleation and initial growth of ice crystals in cirrus clouds at low $(<238 \mathrm{~K})$ temperatures prevailing in the upper troposphere and in the tropopause region is implemented in the ECHAM general circulation model (GCM). With this model we performed the first interactive simulations of cirrus clouds in a global climate model. As homogeneous ice crystal nucleation requires relative humidities with respect to ice of $140-170 \%$ at these temperatures, we abandoned the saturation adjustment scheme previously used to compute the properties of cirrus clouds in GCMs. The comparison with relative humidity data taken on commercial aircraft showed that ECHAM reproduces the frequency distribution of supersaturation with respect to ice in cloud-free regions well especially if high values of the subgrid-scale vertical velocity are assumed. On the other hand, the higher frequency of occurrence of high supersaturations in the model may point to heterogeneous freezing as the missing mechanism for ice formation. We found that homogeneous freezing may be limited by the number of hygroscopic aerosols present. However, as the ice water content remains the same for the natural and present-day aerosol scenarios the longwave radiation does not change. Thus anthropogenic aerosol and precursor emissions have only a small effect on cirrus formed by homogeneous freezing. Aircraft emissions of sulfate aerosols are not likely to be important for cirrus formation. Aircraft soot emissions may be important if the soot particles nucleate ice more efficiently than by homogeneous freezing. INDEX TERMS: 0305 Atmospheric Composition and Structure: Aerosols and particles (0345, 4801); 0320 Atmospheric Composition and Structure: Cloud physics and chemistry; 0345 Atmospheric Composition and Structure: Pollution — urban and regional (0305); KEYWORDS: Cirrus clouds, ice formation, homogeneous freezing, supercooled aerosols, climate modeling

\section{Introduction}

[2] Cirrus clouds cover $\sim 20-40 \%$ of the Earth's surface [Liou, 1986; Wang et al., 1996; Wylie and Menzel, 1999]. They are important regulators of the Earth's radiation budget. According to analyses of satellite measurements taken during the Earth Radiation Budget Experiment (ERBE), the net radiative effect of clouds is to cool the planet by $\sim 20 \mathrm{~W} \mathrm{~m}^{-2}$ in the global annual mean because the cloud albedo effect is larger than the cloud greenhouse effect [Hartmann, 1993]. Cirrus clouds mainly contribute to the cloud greenhouse effect because of their high altitude and their much lower temperature as compared to the underlying surface and their rather small optical depth. These clouds tend to become opaque to upwelling terrestrial radiation quicker than they become reflective to solar radiation; that is, their greenhouse effect dominates over their albedo effect [e.g., Ackerman et al., 1988].

[3] Moreover, the formation of ice in the atmosphere has long been recognized as a topic of great importance due to its key role in the precipitation process. While supersaturations with respect to ice in excess of $40 \%$ are necessary to freeze sulfate haze droplets, far lower supersaturations are needed for heterogeneous freezing of efficient ice nuclei [e.g., Pruppacher and Klett, 1997].

[4] Jensen et al. [1998] observed large ice particle number concentrations in wave clouds with temperatures of $\sim-37^{\circ} \mathrm{C}$. They

Copyright 2002 by the American Geophysical Union. 0148-0227/02/2001JD000767\$9.00 suggested that these ice crystals are caused by the activation of sulfate aerosols in liquid droplets followed by subsequent homogeneous freezing. At colder temperatures $\left(T<-60^{\circ} \mathrm{C}\right)$, high supersaturations with respect to ice are also consistent with theoretical and laboratory studies, suggesting that large supersaturations are required to homogeneously freeze sulfate aerosols [Jensen et al., 1998]. Cziczo and Abbatt [1999] concluded that ammonium sulfate aerosols will freeze at higher temperatures than pure water aerosols and thus will promote cirrus cloud formation in the upper troposphere at higher temperatures and lower relative humidities than previously believed. Chen et al. [2000] studied the freezing behavior of different sulfate compounds and concluded that the size effects on freezing may be more important than the degree of ammoniation of the sulfate compound. This agrees with the findings of Koop et al. [2000] that homogeneous freezing is independent of the chemical nature of the solution but only depends on the water activity of the solution droplets. The water activity of aerosol droplets in the atmosphere, in turn, is largely controlled by the relative humidity.

[5] These findings were used in the parameterization of homogeneous freezing by Kärcher and Lohmann [2002]. The parameterization was derived from first principles, building on the supersaturation and ice crystal growth equations. In contrast to previous parameterizations, this scheme considers the basic physical processes that eventually determine the number of ice crystals $N_{i}$ forming during an adiabatic ascent, including the dependence of $N_{i}$ on temperature and updraft speed. In particular, it was found that the number of crystals in young cirrus clouds, formed via homogeneous 
freezing of aqueous solution droplets, is quite insensitive to details of the aerosol size distribution in many cases but increases rapidly with updraft velocity and decreases with temperature.

[6] State-of-the art general circulation models (GCMs) represent cirrus clouds either by diagnosing the ice water portion from the predicted total water content as a function of temperature [ $\mathrm{Del}$ Genio et al., 1996] or by separately predicting cloud ice mixing ratio [Lohmann and Roeckner, 1996; Fowler et al., 1996]. All of these schemes apply a saturation adjustment scheme for condensation and deposition; that is, supersaturation with respect to ice will be removed within one time step. Only recently, Wilson and Ballard [1999] introduced an ice phase scheme into the UK Meteorological Office Unified Model that allows saturation with respect to ice by explicitly solving the growth equation for a single ice particle.

[7] In this paper, we introduce the parameterization of homogeneous freezing of supercooled solution droplets by Kärcher and Lohmann [2002] into the German general circulation model ECHAM. In order to apply this parameterization we need to abandon the saturation adjustment scheme as explained in section 2. Validation with observations is discussed in section 3. The importance of the mesoscale velocity for cirrus formation, the advection scheme used, and the total number of accumulation and coarse mode aerosols present are investigated in section 4. Section 5 summarizes the results and concludes this paper.

\section{Model Description}

[8] The ECHAM model used in this study is a modified version based on the model by Lohmann et al. [1999a] and Lohmann [2002]. Prognostic aerosol variables are mass mixing ratios of sulfate, hydrophilic and hydrophobic organic carbon (OC), hydrophilic and hydrophobic black carbon (BC), submicron and supermicron dust $(0-1 \mu \mathrm{m}$ and $1-2 \mu \mathrm{m})$, and submicron and supermicron sea salt $(0-1 \mu \mathrm{m}$ and $1-10 \mu \mathrm{m})$. The total number of hygroscopic aerosols $N_{a}$ that is used as the upper bound for the number of homogeneously frozen haze droplets $N_{i}$ is obtained by assuming an externally mixed aerosol:

$$
N_{a}=N_{\text {sea salt }}+N_{\mathrm{BC}}^{\text {phil }}+N_{\mathrm{OC}}^{\text {phil }}+N_{\text {dust }}+N_{\mathrm{SO}_{4}} .
$$

We convert the mass of each aerosol component into an aerosol number assuming a separate lognormal distribution, density, variance, and a mode radius typical for each species following Hess et al. [1998]. For more details we refer to Lohmann et al. [1999a]. Note that in the experiments described in this study the minimum number of aerosol particles assumed to always be present has been reduced from $300 \mathrm{~cm}^{-3}$ to a lower bound of 1 particle $\mathrm{cm}^{-3}$. We previously used the background concentration of $300 \mathrm{~cm}^{-3}$ aerosols because we were only looking at water clouds. This had to be changed in order to extend the existing microphysical model framework in ECHAM to treat homogeneous freezing processes. The value of the lower bound to be used is uncertain, and a more detailed aerosol module is required to obtain a refined description.

[9] The prognostic cloud variables, the mass mixing ratios of cloud liquid water and cloud ice, and the number concentrations of cloud droplets and ice crystals are described by Lohmann and Roeckner [1996], Lohmann et al. [1999a], and Lohmann [2002]. Cloud cover is diagnosed from relative humidity following Sundqvist et al. [1989]. In order to get rid of the saturation adjustment scheme the parameterization of the depositional growth of ice crystals by homogeneous and heterogeneous nucleation $Q_{\text {dep }}$ $\left(\mathrm{kg} \mathrm{kg}^{-1} \mathrm{~s}^{-1}\right)$ has been adopted from the mesoscale model GESIMA [Levkov et al., 1992] in the simulation HOM:

$$
Q_{\text {dep }}=\left(\frac{\partial q_{i}}{\partial t}\right)_{\text {dep }}=4 \pi C A_{T} f_{R e}\left(S_{i}-1\right) N_{i}
$$

where $q_{i}$ is the ice water mixing ratio, $C$ is the capacitance of an ice crystal evaluated as a spherical particle such that $C=D_{i} / 2$ (where $D_{i}$ is the particle diameter), $f_{R e}$ is the ventilation factor as a function of the Reynolds number, $S_{i}$ is the saturation ratio over ice at the beginning of the time step, $N_{i}$ is the ice crystal number concentration, and $A_{T}$ is defined as

$$
A_{T}=\left\{\rho\left[\frac{L_{s}}{k_{a} T}\left(\frac{L_{s}}{R_{v} T}-1\right)+\frac{R_{v} T}{D_{v} e_{s i}}\right]\right\}^{-1}
$$

where $T$ is the temperature, $L_{s}$ is the latent heat of sublimation, $k_{a}$ is the thermal conductivity of air, $R_{v}$ is the gas constant of water vapor, $D_{v}$ is the diffusivity of water vapor in air, and $e_{s i}$ is the saturation vapor pressure over a plane ice surface.

[10] In simulation HOM the number of newly frozen ice crystals at temperatures below $-35^{\circ} \mathrm{C}$ is obtained from the parameterization by Kärcher and Lohmann [2002]:

$$
N_{i}^{\mathrm{HOM}}=\min \left[\frac{m_{w}}{\rho_{i}}\left(\frac{b_{2}}{2 \pi b_{1}}\right)^{3 / 2} \frac{a_{1} S_{c r}}{a_{2}+a_{3} S_{c r}} \frac{w}{\sqrt{\tau}} ; N_{a}\right]
$$

where $m_{w}$ is the molecular weight of water, $\rho_{i}$ is the ice crystal density $\left(=925 \mathrm{~kg} \mathrm{~m}^{-3}\right), S_{c r}$ is the critical supersaturation where freezing commences, $w$ is the updraft velocity, $\tau \propto 1 / w$ is the characteristic timescale of the nucleation event, and $a_{1}, a_{2}=1 / N_{s i}$, $a_{3}, b_{1} \propto N_{s i}\left(S_{c r}-1\right), b_{2}$ are temperature-dependent variables explained by Kärcher and Lohmann [2002]. Finally, $N_{s i}(T)$ denotes the water vapor number density at ice saturation. Recall that the nucleation rate is limited by the number of hygroscopic aerosol particles $N_{a}$. As shown by Kärcher and Lohmann [2002], one can deduce the approximate scaling relationship

$$
N_{i}^{\mathrm{HOM}} \propto w^{3 / 2} N_{s i}^{-1 / 2}(T)
$$

The mesoscale updraft velocity $w$ is obtained as the sum of the grid mean vertical velocity and a turbulent contribution expressed in terms of the turbulent kinetic energy (TKE) [Lohmann et al., 1999a]:

$$
w=\bar{w}+0.7 \sqrt{\mathrm{TKE}} .
$$

[11] In deriving (3), Kärcher and Lohmann [2002] argued that aerosol size effects on the homogeneous freezing process are unimportant whenever the initial growth timescale of the ice particles is shorter than the timescale of the nucleation event. The former is inversely proportional to $N_{s i}$ (exhibiting an exponential dependence on $T$ ), and the latter is inversely proportional to $w$. The curve in Figure 1 separates the regions in terms of $T$ and $w$ in which size effects may be neglected (above the curve) or are important (below the curve), as discussed by Kärcher and Lohmann [2002]. The curve has been evaluated assuming a freezing particle radius $r_{0}$ of $0.25 \mu \mathrm{m}$, a typical size of a freezing aerosol particle. The symbols in Figure 1 are representative samples taken from the ECHAM model. In Figure 1 (top) we used (5) and in Figure 1 (bottom) we enhance the TKE term by a factor 1.9 as explained in section 4 . Figure 1 shows that in the ECHAM model, most of the time, cirrus form under conditions where aerosol size effects do not play a substantial role in determining $N_{i}$, supporting the use of the simple parameterization (3). It should be noted, however, that the curve shifts to the left when $r_{0}$ increases, thereby reducing the parameter space where (3) is valid.

[12] In simulation HOM the number of newly formed ice crystals in the temperature range between 0 and $-35^{\circ} \mathrm{C}$ is obtained 

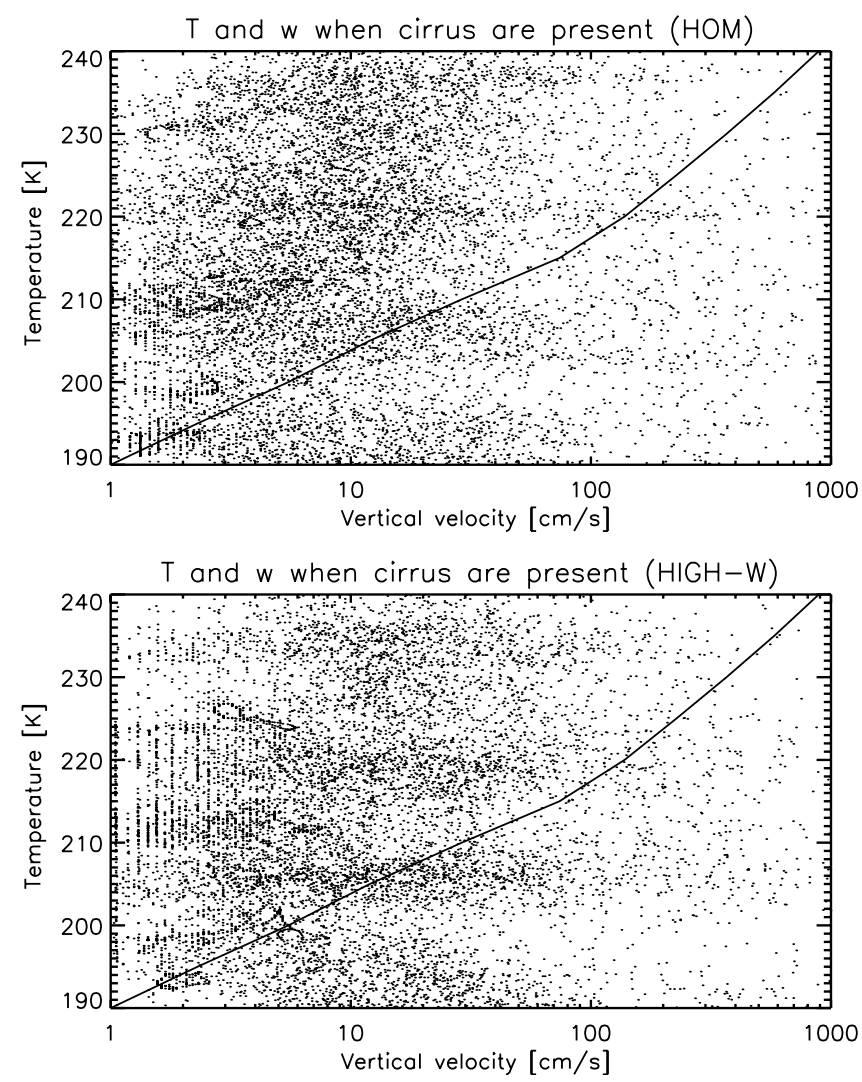

Figure 1. Scatterplot of ECHAM temperature and vertical velocity values (top) when cirrus are present using (5) and (bottom) with enhanced turbulent contributions to the vertical velocity. The curve connects the values of vertical velocity and freezing temperature for which the timescales of the freezing event and the initial growth of the ice crystals are identical, evaluated for an initial particle radius of $0.25 \mu \mathrm{m}$ [Kärcher and Lohmann, 2002]. The regions above (below) the curve indicate combinations of these parameters for which aerosol size effects on the freezing process are small (large).

from the parameterization of heterogeneous deposition-condensation freezing by Meyers et al. [1992]:

$$
N_{i}^{\text {het }}=\exp \left(-0.639+0.1296 S_{i}\right)
$$

[13] In the reference simulation (REF), neither the parameterization of heterogeneous deposition-condensation freezing (6) nor the parameterization of homogeneous freezing (3) is used. In REF the cirrus cloud water content is obtained using a saturation adjustment scheme. From that the number of newly formed ice crystals is obtained as follows: First, the effective ice crystal radius $r_{i e}(\mu \mathrm{m})$ is determined. It is parameterized as a function of temperature based on observations from midlatitude cirrus by $\mathrm{Ou}$ and Liou [1995]:

$r_{i e}=0.5\left[326.3+12.4\left(T-T_{0}\right)+0.2\left(T-T_{0}\right)^{2}+0.001\left(T-T_{0}\right)^{3}\right]$,

where $T_{0}=273.16 \mathrm{~K}$.

[14] Second, the mean volume radius $r_{i v}(\mathrm{~m})$ is determined by empirically relating it to the effective ice crystal radius $r_{i e}$ from simultaneous measurements of the two radii (S. Moss, personal communication, 1996):

$$
r_{i v}=10^{-6} \sqrt[3]{\beta+\sqrt{\gamma+\delta r_{i e}^{3}}}
$$

where $\beta=-2.261 \times 10^{3}, \gamma=5.113 \times 10^{6}$, and $\delta=2.809 \times 10^{3}$. With that the newly formed ice crystal number concentration is given as

$$
N_{i}=\frac{3 \rho_{0} q_{i}^{\text {new }}}{4 \pi \rho_{i} r_{i v}^{3}},
$$

where $\rho_{\mathrm{i}}\left(=500 \mathrm{~kg} \mathrm{~m}^{-3}\right)$ is the ice crystal density, $\rho_{0}$ is the air density, and $q_{i}^{\text {new }}$ refers to either the detrained ice water mixing ratio or the ice water mixing ratio calculated from the saturation adjustment scheme used for deposition. $N_{i}$ together with $q_{i}$ is then used to calculate the volume mean ice crystal size that is used in the parameterization of the aggregation rate and for the cloud optical depth.

\section{Comparison With Observations}

\subsection{Frequency of Occurrence of Relative Humidity}

[15] The simulations REF, HOM, and NAT-AP (see section 4) were conducted in T30 horizontal resolution with 19 vertical levels over a period of 3 years after an initial spin-up of 3 months using climatological sea surface temperatures. The sensitivity experiments HIGH-W and TRANSP (see section 4) were only integrated over 1 year after the spin-up. We first evaluate ECHAM's ability to simulate supersaturations with respect to ice. As the reference simulation does not allow any ice supersaturation at temperatures below $-35^{\circ} \mathrm{C}$, we use simulation HOM that includes the new cirrus parameterization of homogeneous freezing of solution droplets. 

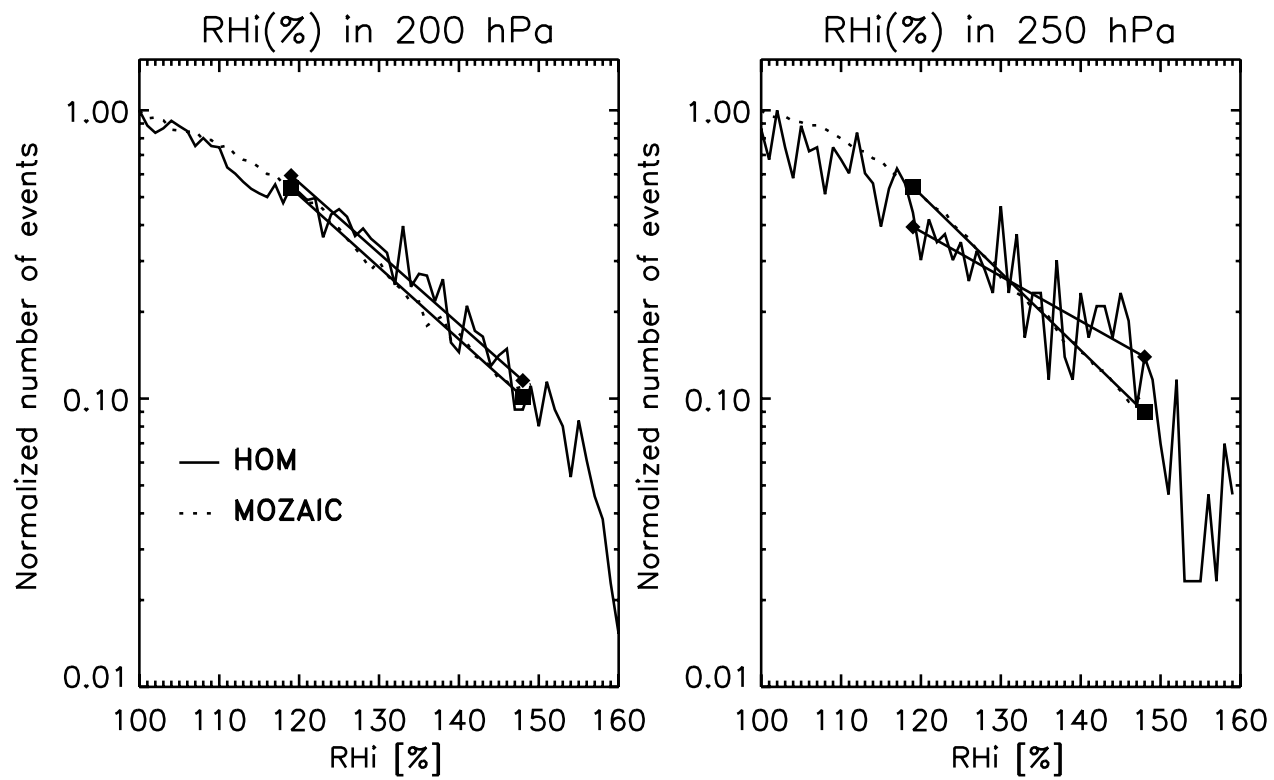

Figure 2. Normalized frequency distribution of relative humidity with respect to ice in two layers centered around 200 and $250 \mathrm{hPa}$ for cloud-free conditions from MOZAIC observations and simulation HOM. The solid lines refer to the slopes summarized in Table 1. See color version of this figure at back of this issue.

[16] Gierens et al. [1999] analyzed 3 years of MOZAIC (measurement of ozone on Airbus in-service aircraft) measurements and derived a distribution law for the relative humidity in the upper troposphere and lower stratosphere. They determined the frequency distribution of relative humidity with respect to water and ice for stratospheric and tropospheric air in two layers centered around 200 and $250 \mathrm{hPa}$ for cloud-free conditions. We also extracted relative humidity with respect to ice $\left(\mathrm{RH}_{i}\right)$ from 1 year of ECHAM data for cloud-free pixels in the same two layers as shown in Figure 2. We limited the data to the North Atlantic flight corridor $\left(30^{\circ} \mathrm{N}\right.$ to $90^{\circ}$ and $80^{\circ}$ to $\left.0^{\circ}\right)$ where most of the MOZAIC data were taken.

[17] The MOZAIC data of $\mathrm{RH}_{i}$ decrease exponentially with increasing relative humidities above $100 \%$, very similar to what is seen in ECHAM. The slope describing the decrease in frequency of relative humidity between $119 \%$ and $148 \%$ in $200 \mathrm{hPa}$ is the same in ECHAM as in the MOZAIC data (see also Table 1). It is, however, lower than observed in $250 \mathrm{hPa}$. Here ECHAM predicts high relative humidities in excess of $130 \%$ more often than observed. This could have two reasons. The subgrid-scale vertical velocity could be too low, so that not enough ice crystals are formed and the ice crystals are not numerous enough for sufficient water vapor molecules to deposit onto them. Recall the strong dependence of $N_{i}^{\mathrm{HOM}}$ on $w$ as expressed in (4). This hypothesis is studied in a sensitivity experiment below. On the other hand, the discrepancy between more frequently simulated high $\mathrm{RH}_{i}$ than observed could point to heterogeneous nucleation as one important mechanism that is currently lacking in our description of cirrus formation.

Table 1. Slopes for Frequency of Occurrence of Relative Humidity With Respect to Ice $\left(\mathrm{RH}_{i}\right)$ Averaged Over $119-148 \%$ in Two Different Levels (200 and $250 \mathrm{hPa}$ ) From the MOZAIC Data (OBS) and Simulations HOM, HIGH-W, and TRANSP

\begin{tabular}{lcccc}
\hline & HOM & HIGH-W & TRANSP & OBS \\
\hline $\mathrm{RH}_{i}^{200 \mathrm{hPa}}$ & -0.025 & -0.024 & -0.014 & -0.025 \\
$\mathrm{RH}_{i}^{250 \mathrm{hPa}}$ & -0.016 & -0.023 & -0.014 & -0.027 \\
\hline
\end{tabular}

\subsection{Frequency of Occurrence of Thin Cirrus}

[18] Mace et al. [2001] studied the frequency of occurrence of cirrus for a given large-scale vertical velocity as well as the frequency distribution of vertical velocity whenever cirrus clouds
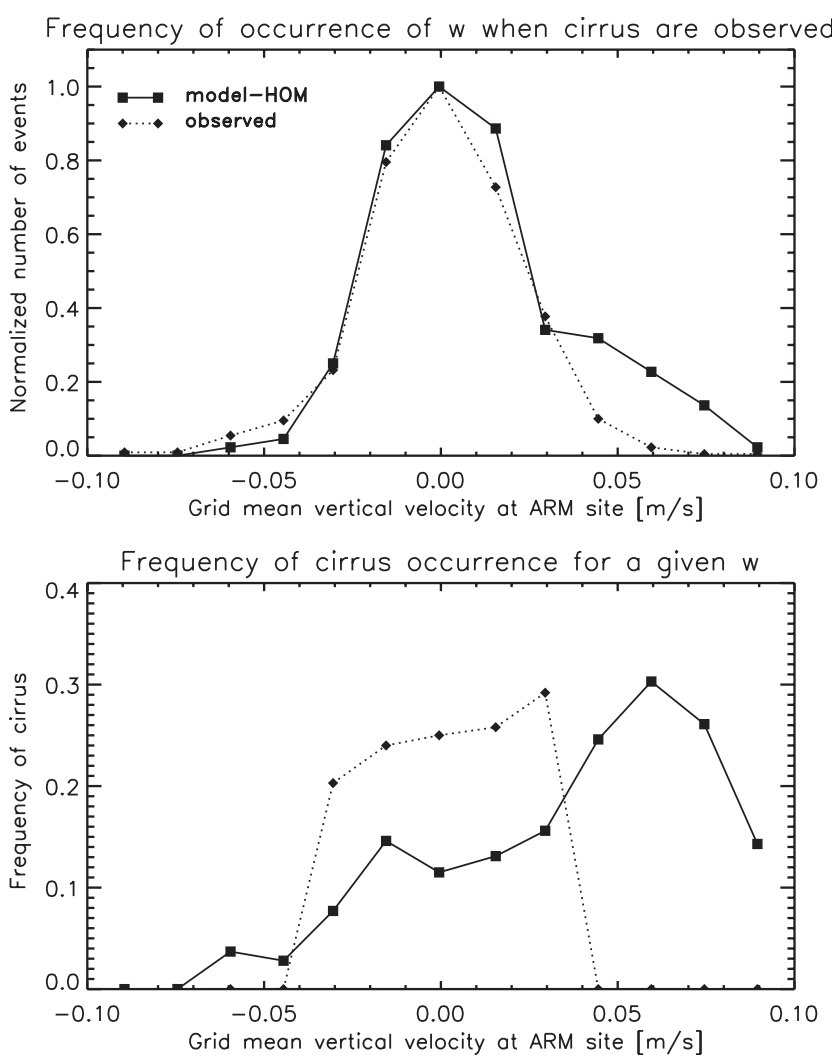

Figure 3. (top) Frequency distribution of vertical velocity when cirrus is present and (bottom) frequency of occurrence of cirrus for a given vertical velocity at the ARM site in Oklahoma. 

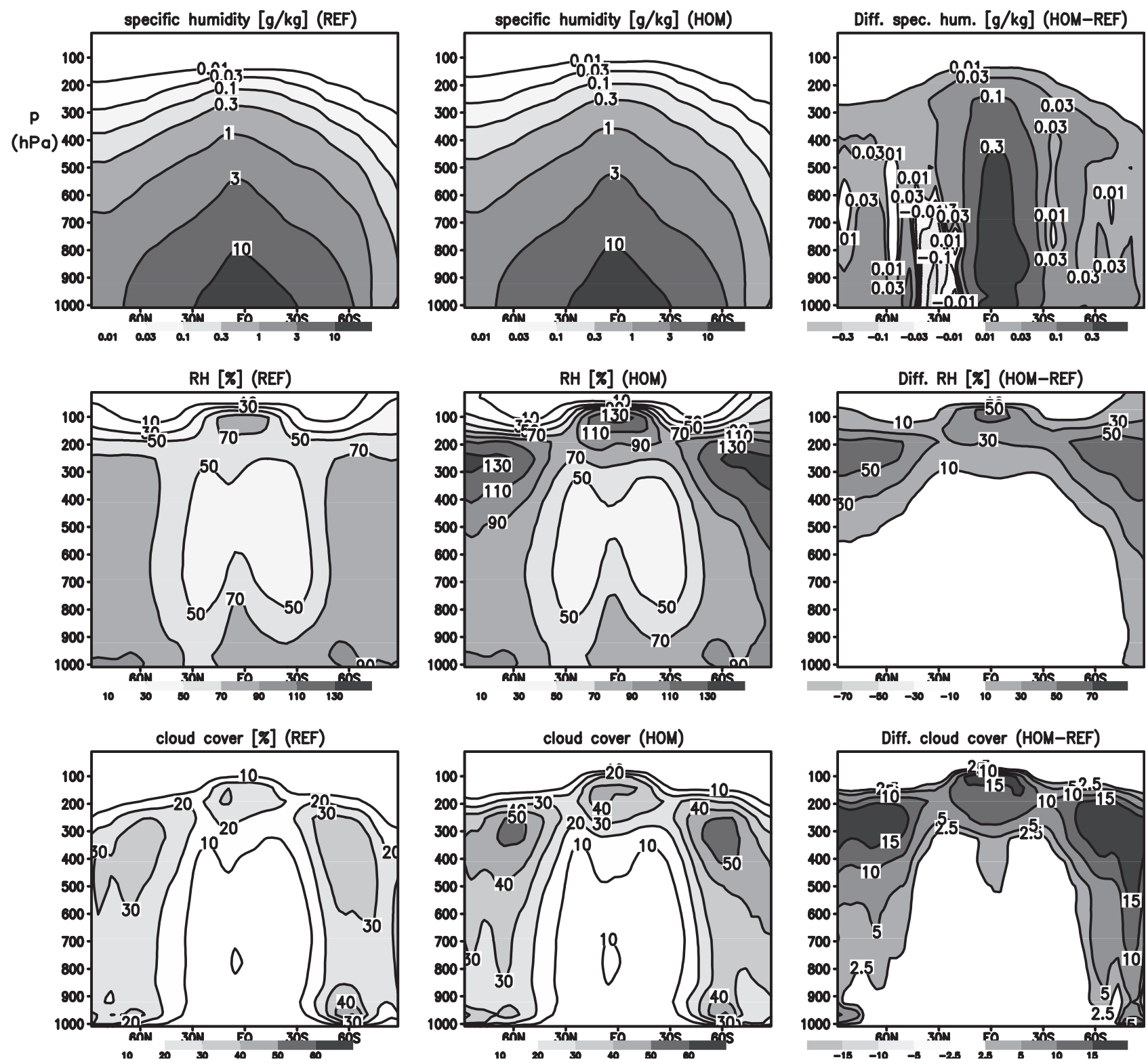

Figure 4. Annual zonal mean latitude versus pressure cross sections of specific humidity $\left(\mathrm{g} \mathrm{kg}^{-1}\right)$, relative humidity $(\mathrm{RH})(\%)$, and cloud cover (\%) for the simulations REF, HOM, and the difference HOM - REF.

are present for 1 year of $8-\mathrm{mm}$ cloud radar data taken at the Atmospheric Radiation Measurements (ARM) site in Oklahoma (Figure 3). The ECHAM data are also taken for 1 year from the grid point closest to the ARM site.

[19] There seems to be little correlation between the large-scale vertical velocity and the occurrence of cirrus clouds. This can be caused by one of the following reasons. First, cirrus formation is mostly caused by small-scale and mesoscale motions that are much stronger than the large-scale vertical velocity. Second, cirrus formation occurs at large-scale upward motions but decays slowly enough that remnants and virga are still visible when large-scale subsidence prevails. Most frequently, the large-scale vertical velocity $(\bar{w})$ is around $0 \mathrm{~m} \mathrm{~s}^{-1}$ when cirrus are observed both in the observations and in ECHAM. The frequency distribution of $\bar{w}$ when cirrus is observed is very well captured in ECHAM, but ECHAM deviates from the observations in terms of cirrus occurrence for a given $\bar{w}$. That may be attributed to the more frequent positive $\bar{w}$ occurrence in ECHAM as compared to the observations. Both
ECHAM and ARM data report cirrus more often for large-scale upward motion than for large-scale subsidence.

\subsection{Zonal Mean and Geographical Distributions}

[20] Figures 4 and 5 show annual zonal mean latitude versus pressure cross sections of specific and relative humidity, cloud cover and ice water mixing ratio, and ice crystal number concentrations for the simulations REF and HOM. Here the relative humidity is a hybrid of relative humidity with respect to water at temperatures above $273.2 \mathrm{~K}$, with respect to ice at temperatures below $238.2 \mathrm{~K}$, and a mixture of these two for temperatures between 238.2 and $273.2 \mathrm{~K}$, depending on the presence of ice clouds [Lohmann and Roeckner, 1996].

[21] The relative humidity has maxima near the surface, in the polar regions, and in the upper tropical troposphere. The upper zonal mean maxima are increased in HOM to above $130 \%$ below the tropical and polar tropopause caused by the increase in specific humidity. B. Steil (personal communication, 2001), and colleagues 

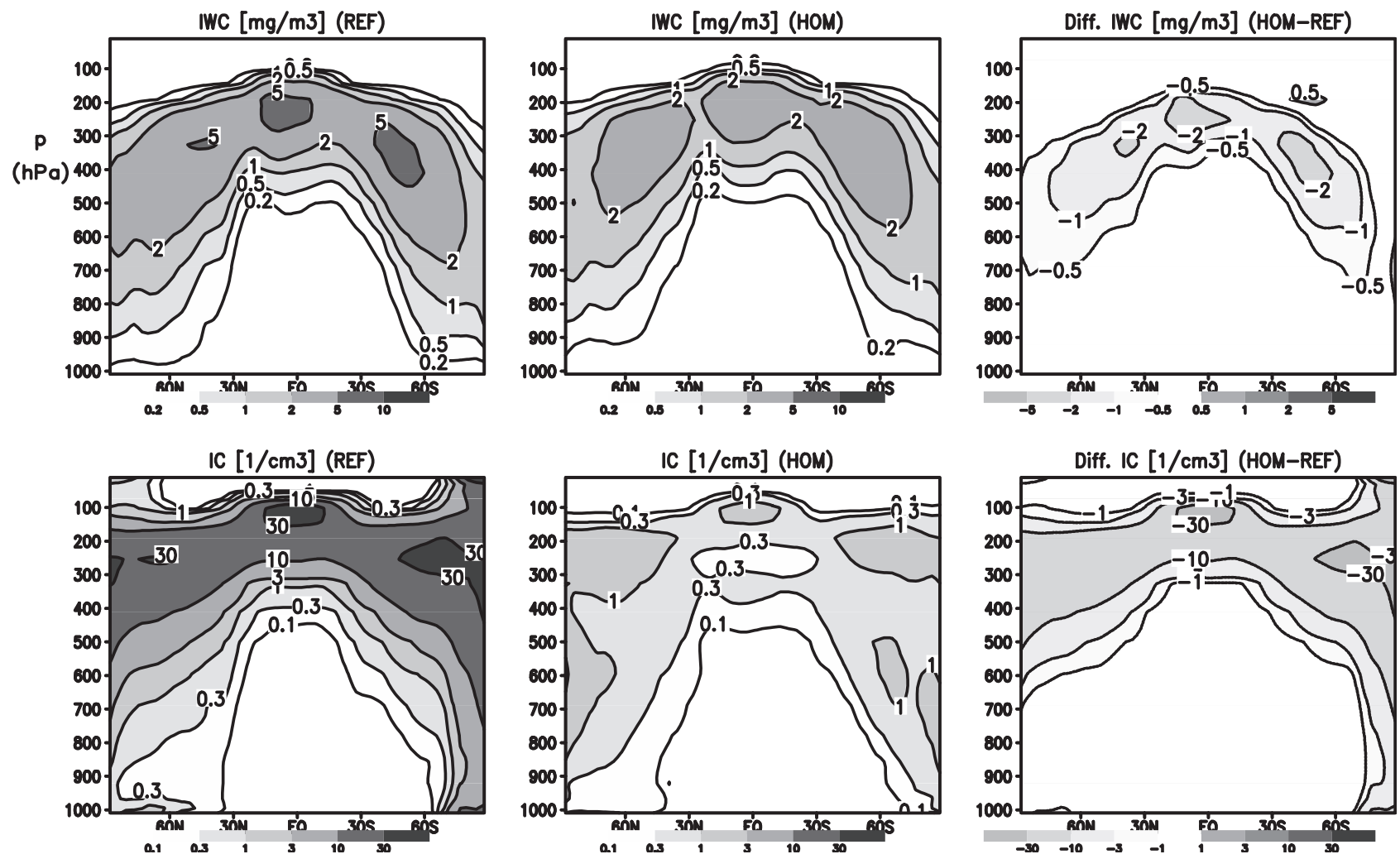

Figure 5. Annual zonal mean latitude versus pressure cross sections of ice water content $\left(\mathrm{mg} \mathrm{m}^{-3}\right)$ and ice crystal number concentrations $\left(\mathrm{cm}^{-3}\right)$ for the simulations REF, HOM, and the difference HOM - REF

compared water vapor mixing ratios from the middle atmosphere version of ECHAM with satellite observations from the Halogen Occultation Experiment (HALOE). They found that ECHAM simulates excessive water vapor at higher altitudes of the polar regions causing the hygropause to be too high. Moreover, ECHAM has a cold bias in the polar upper troposphere [Roeckner et al., 1996]. This model artifact has been amplified in HOM now that deposition does not set in at $100 \% \mathrm{RH}_{i}$ and the relative humidity has increased by up to $50 \%$. Likewise, the cloud cover is higher in these regions. It increases by $15 \%$ on average. This increase in cloud cover would lead to an increase in longwave cloud forcing. Since we constrain the model to match the observed global annual mean longwave and shortwave cloud forcing from ERBE, we enhanced the aggregation rate of ice particles into snow by a factor of 3 , resulting in a faster removal of water from the atmosphere. This is permitted because all cloud microphysics parameterization are very uncertain when applied to climate model grid scales [see Rotstayn, 2000]. With this adjustment the longwave cloud forcing in $\mathrm{HOM}$ is within $1 \mathrm{~W} \mathrm{~m}^{-2}$ of the observed one (Table 2).

[22] As a consequence of increasing the aggregation rate, the ice water content is reduced in HOM as compared to REF (Figure 5). At the same time the number of ice crystals has decreased in HOM everywhere by roughly an order of magnitude. The maximum zonal mean concentrations of at least $1 \mathrm{~cm}^{-3}$ in HOM are located in the upper tropical and polar troposphere.

[23] The comparison of annual zonal means of cloud cover and net cloud forcing with observations is shown in Figure 6. Here the new International Satellite Cloud Climatology Project (ISCCP) cloud data set D2 [Rossow and Schiffer, 1999] is used. In the ISCCP-D2 data set the global mean cloud cover has increased from $62 \%$ in the ISCCP-C data set to $67 \%$ in ISCCP-D2. By decreasing biases in cirrus detection sensitivity over land and reducing biases in cirrus cloud properties the high level cloud cover has increased from
$14 \%$ to $22 \%$. The satellite observations of the Stratosphere Aerosol and Gas Experiment (SAGE) still detect more high clouds than ISCCP because ISCCP cannot detect cirrus clouds with optical depths $<0.1$ [Liao et al., 1995] where SAGE is especially sensitive [Wang et al., 1996].

[24] Most noticeably, total cloud cover and especially high cloud cover have increased significantly in HOM as compared to REF. The total cloud cover increased by $12 \%$ in the global mean dominated by the large increase in high cloud cover by $18 \%$ (Table 2 ). Whereas the increase in the tropics is in better agreement with the observations, the increase in extratropical high clouds caused by the increase in specific humidity is not supported by observations. Note that cloud cover and cloud water content are not consistently treated in ECHAM. That is, cloud cover depends only on relative humidity but is independent of the cloud water content [see Roeckner et al., 1996].

[25] The ice water path has decreased everywhere in HOM. The decrease amounts to $4 \mathrm{~g} \mathrm{~m}^{-2}$ in the global mean (Table 2) because of the faster aggregation rate. The net cloud forcing is very similar in both simulations. It is more negative than observed at the equator caused by excessive liquid water detrained from shallow convection [see also Lohmann, 2002]. A common feature in many GCMs including ECHAM is a too small shortwave cloud forcing over midlatitude oceans causing the net cloud forcing to be too small. The changes in longwave radiation are more pronounced in cloud forcing than in clear-sky radiation. The higher cloud cover in HOM caused an increase in longwave cloud forcing of $4 \mathrm{~W} \mathrm{~m}^{-2}$ as compared to REF. Conversely the higher water vapor content in the upper troposphere in HOM caused a decrease in the clear-sky outgoing longwave radiation by $2.4 \mathrm{~W} \mathrm{~m}^{-2}$ as compared to REF (Table 2).

[26] Figure 7 shows the vertically integrated ice crystal number concentration for the simulations REF and HOM. Maxima in column ice crystal number are associated with deep convection in 
Table 2. Global Annual Mean Ice Water Path (IWP), Shortwave (SCF) and Longwave (LCF) Cloud Forcing, and Clear-Sky Outgoing Longwave Radiation $\left(\mathrm{LW}_{c s}\right)$ at the Top of the Atmosphere and Total (TCC) and High (HCC) Cloud Cover for the Simulations REF, HOM, HIGH-W, TRANSP, and NAT-AP Together With Observations of the Cloud Forcings From ERBE, TCC, and HCC From ISCCP and HCC From SAGE (Higher Value)

\begin{tabular}{|c|c|c|c|c|c|c|}
\hline & REF & HOM & HIGH-W & TRANSP & NAT-AP & OBS \\
\hline IWP, $\mathrm{g} \mathrm{m}^{-2}$ & 11.9 & 8.0 & 8.2 & 7.0 & 7.9 & \\
\hline $\mathrm{SCF}, \mathrm{W} \mathrm{m}^{-2}$ & -44.0 & -50.2 & -50.5 & -38.6 & -49.2 & -49.1 \\
\hline $\mathrm{LCF}, \mathrm{W} \mathrm{m}^{-2}$ & 29.8 & 33.8 & 34.4 & 19.4 & 33.8 & 29.7 \\
\hline $\mathrm{LW}_{c s}, \mathrm{~W} \mathrm{~m}^{-2}$ & 262.3 & 259.9 & 259.9 & 260.7 & 259.9 & 265 \\
\hline TCC, $\%$ & 59.1 & 70.7 & 71.0 & 61.7 & 71.4 & 67.3 \\
\hline $\mathrm{HCC}, \%$ & 30.6 & 48.6 & 45.2 & 36.9 & 45.7 & $21.8 / 33.6$ \\
\hline
\end{tabular}

the tropics and with high clouds in polar regions. The latter are overestimated by the cold and wet bias in the polar upper troposphere, as mentioned above. In HOM both the ice water content and ice crystal number concentrations associated with deep convective regions and in polar high clouds have decreased significantly.

\section{Sensitivity Studies}

\subsection{Design of the Model Experiments}

[27] We investigate the sensitivity of the relative humidity in the clear-sky upper troposphere to the subgrid-scale vertical velocity.
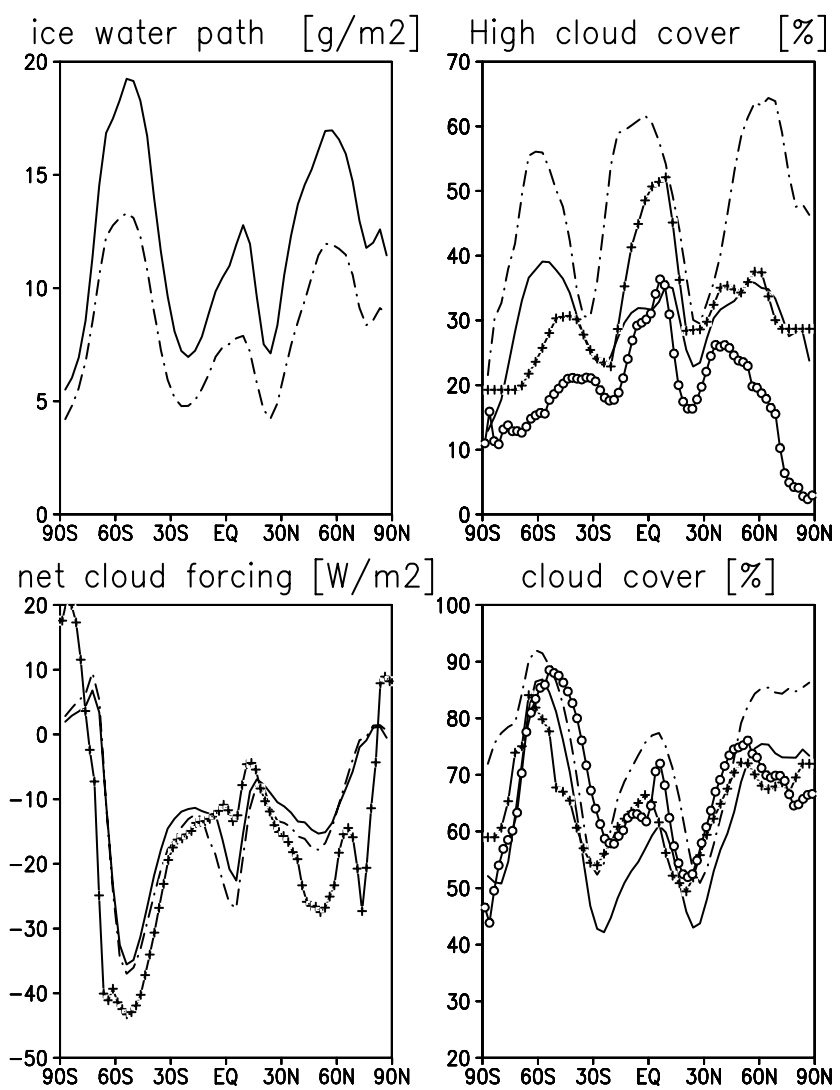

Figure 6. Annual zonal means of ice water path $\left(\mathrm{g} \mathrm{m}^{-2}\right)$, high level cloud cover (\%), total cloud cover (\%), and net cloud forcing $\left(\mathrm{W} \mathrm{m}^{-2}\right.$ ) for the simulations REF (solid line), HOM (dot-dashed line), and observations. Observations for high cloud cover are SAGE data (pluses) and ISCCP (circles); for total cloud cover the data are surface observations by Hahn et al. [1994] (pluses) and ISCCP (circles), and cloud forcing is from ERBE (pluses).
The vertical velocity in (5) is replaced by $w=\bar{w}+1.33 \sqrt{\mathrm{TKE}}$ corresponding roughly to the $95 \%$ percentile of a lognormal distribution of $w$ (experiment HIGH-W). We chose this value because Lin and Leaitch [1997] found from measurements taken during the North Atlantic Regional Experiment (NARE) that cloud droplet nucleation is better parameterized in terms of the largest vertical velocities instead of mean vertical velocities.

[28] Also, we study the importance of the advective transport scheme. In the reference experiment we use the semi-Lagrangian transport scheme of Rasch and Williamson [1990]. No semiLagrangian scheme is per se mass conserving because of the interpolation of the Lagrangian departure points onto a regular grid at every time step. Therefore the masses of water vapor and cloud water and the aerosol mass mixing ratios are conserved by employing a mass fixer. Rasch and Lawrence [1998] developed a

\section{simulation REF}

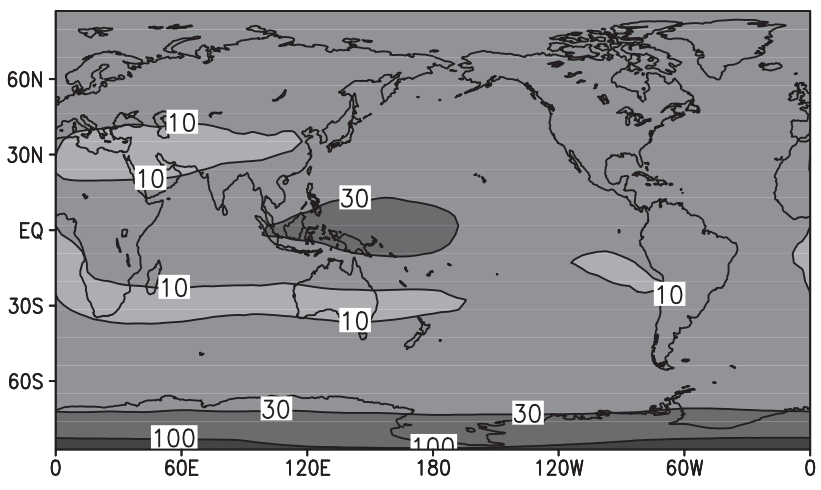

simulation HOM

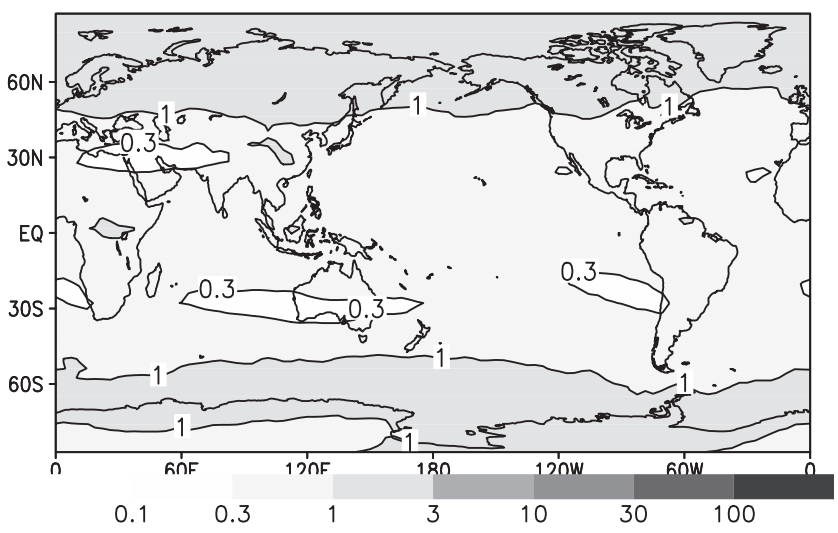

Figure 7. Vertically integrated ice crystal number concentration $\left(10^{6} \mathrm{~cm}^{-2}\right)$ for simulations (top) REF and (bottom) HOM. 

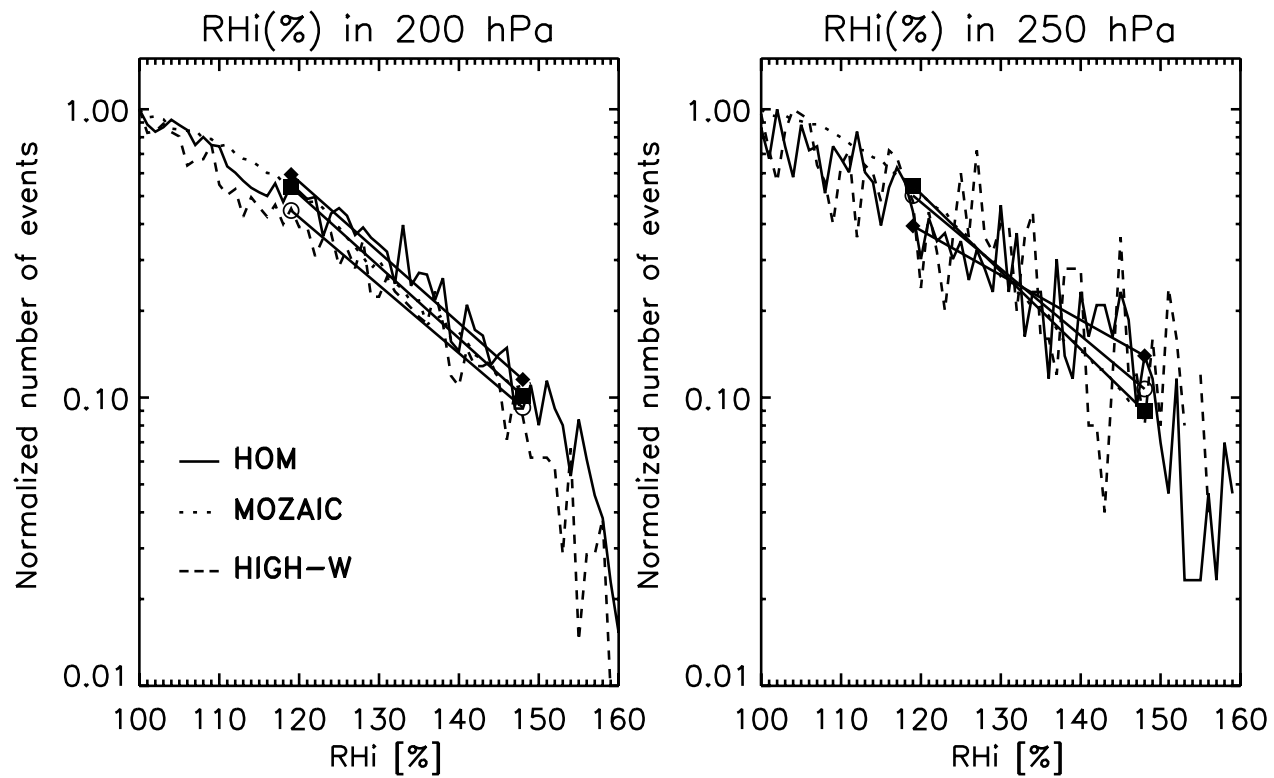

Figure 8. Normalized frequency distribution of relative humidity with respect to ice in two layers centered around 200 and $250 \mathrm{hPa}$ for cloud-free conditions from MOZAIC observations and the simulations HOM and HIGH-W. See color version of figure at back of this issue.

new transport scheme Spitfire by introducing a separate mass continuity equation and casting it in flux form. Thus it now conserves tracer mass and is almost monotonic. We implement it in experiment TRANSP.

[29] Finally, we performed a simulation where the total number of aerosols, which serves as the upper bound for the number of ice crystals formed by homogeneous freezing below $-35^{\circ} \mathrm{C}$ and determines the number of newly formed cloud droplets, is obtained from the natural aerosols sea salt, dust, sulfate produced from dimethyl sulfide or volcanic $\mathrm{SO}_{2}$, and organic aerosols produced from natural forest emissions only (simulation NAT-AP).

\subsection{Results and Discussion}

[30] $\mathrm{RH}_{i}$ in supersaturated clear-sky regions in HIGH-W agrees better with observations than in HOM (Table 1 and Figure 8). This results from the higher number of ice crystals produced at larger vertical velocities (recall (4)). Thus higher relative humidities are more often favorable for ice nucleation to occur, and therefore their frequency of occurrence is reduced, in better agreement with observations in $250 \mathrm{hPa}$.

[31] On the contrary, the new transport scheme changes the frequency distributions for the worse (Table 1 and Figure 9). Since the Spitfire transport scheme is superior to the standard semiLagrangian transport scheme, the better agreement of high relative
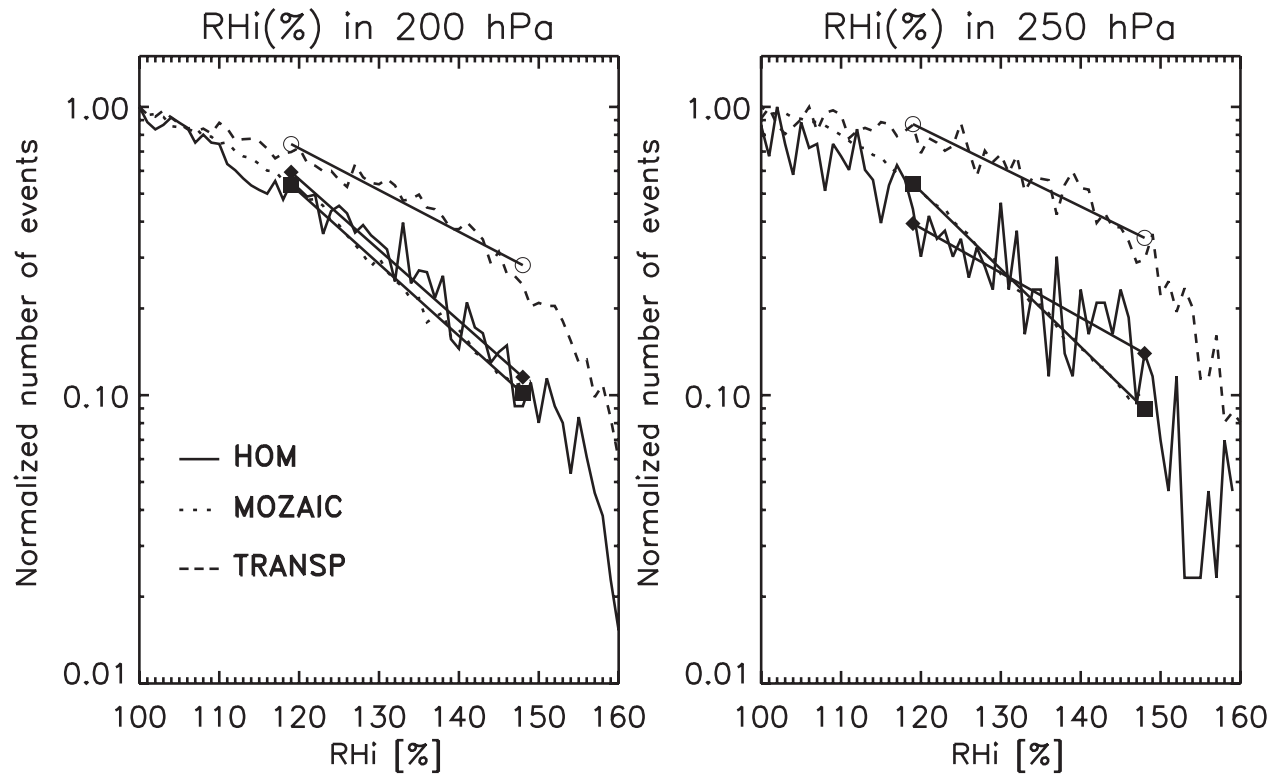

Figure 9. Normalized frequency distribution of relative humidity with respect to ice in two layers centered around 200 and $250 \mathrm{hPa}$ for cloud-free conditions from MOZAIC observations and the simulations HOM and TRANSP. See color version of figure at back of this issue. 

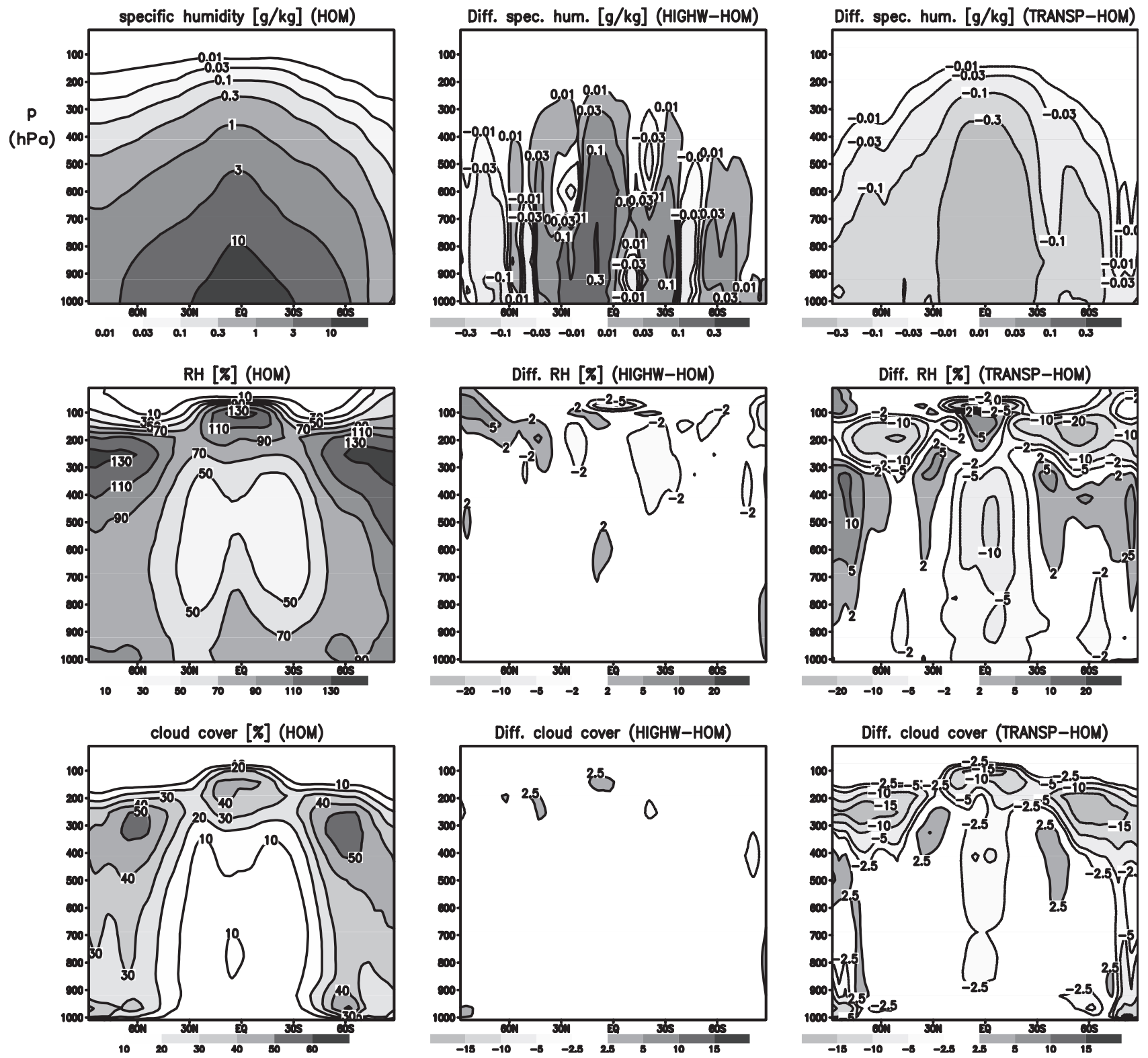

Figure 10. Annual zonal mean latitude versus pressure cross sections of specific humidity $\left(\mathrm{g} \mathrm{kg}^{-1}\right)$, relative humidity $(\mathrm{RH})(\%)$, and cloud cover $(\%)$ for the simulation HOM and the differences HIGH-W - HOM and TRANSP - HOM.

humidities with MOZAIC data in HOM may be due to wrong reasons. That is, the application of the mass fixer in HOM partially counteracts the advection. Everywhere less water vapor is advected vertically in TRANSP (Figure 10). Between 200 and $300 \mathrm{hPa}$ the temperature has decreased in the tropics and increased in midlatitudes in TRANSP so that the relative humidity is reduced in the upper troposphere of the midlatitudes and increased in the tropics as compared to HOM (Figure 10). Going along with a changed mean relative humidity distribution, the cloud cover has decreased by up to $15 \%$ in the upper troposphere in TRANSP. At the same time the frequency of occurrence has changed when the Spitfire transport scheme is used. The atmosphere is now more often highly supersaturated with respect to ice, in worse agreement with observations (Figure 9). However, as argued before, either the subgrid-scale vertical velocity is too small to nucleate sufficient ice nuclei or heterogeneous freezing is a missing physical mechanism for cirrus formation. Moreover, the parameterization of depositional growth depends on a simplified ventilation factor and assumes always spherical particles; both factors could also contribute to the disparity.

[32] In TRANSP in the 200-300 hPa region the total vertical velocity (sum of large scale and subgrid scale) is, on average, reduced by more than $1 \mathrm{~cm} \mathrm{~s}^{-1}$ as compared to HOM (Figure 11). This reduction in vertical velocity is sufficient to considerably reduce the zonal mean number of ice crystals by up to $2 \mathrm{~cm}^{-3}$, as shown in Figure 11. On the contrary, larger subgrid-scale velocities in HIGH-W increase the ice crystal number concentration by up to $1 \mathrm{~cm}^{-3}$ as compared to HOM.

[33] The comparison with observations indicates that the total cloud cover has hardly changed in the sensitivity experiment HIGH-W but is reduced by $9 \%$ in the global annual mean in TRANSP as compared to HOM (Figure 12). Changes in high cloud cover are even more pronounced. The new transport scheme reduces the excessively high cloud cover everywhere in better agreement with observations. At the same time the net cloud forcing is more negative over the Southern Ocean, also an improved feature. 

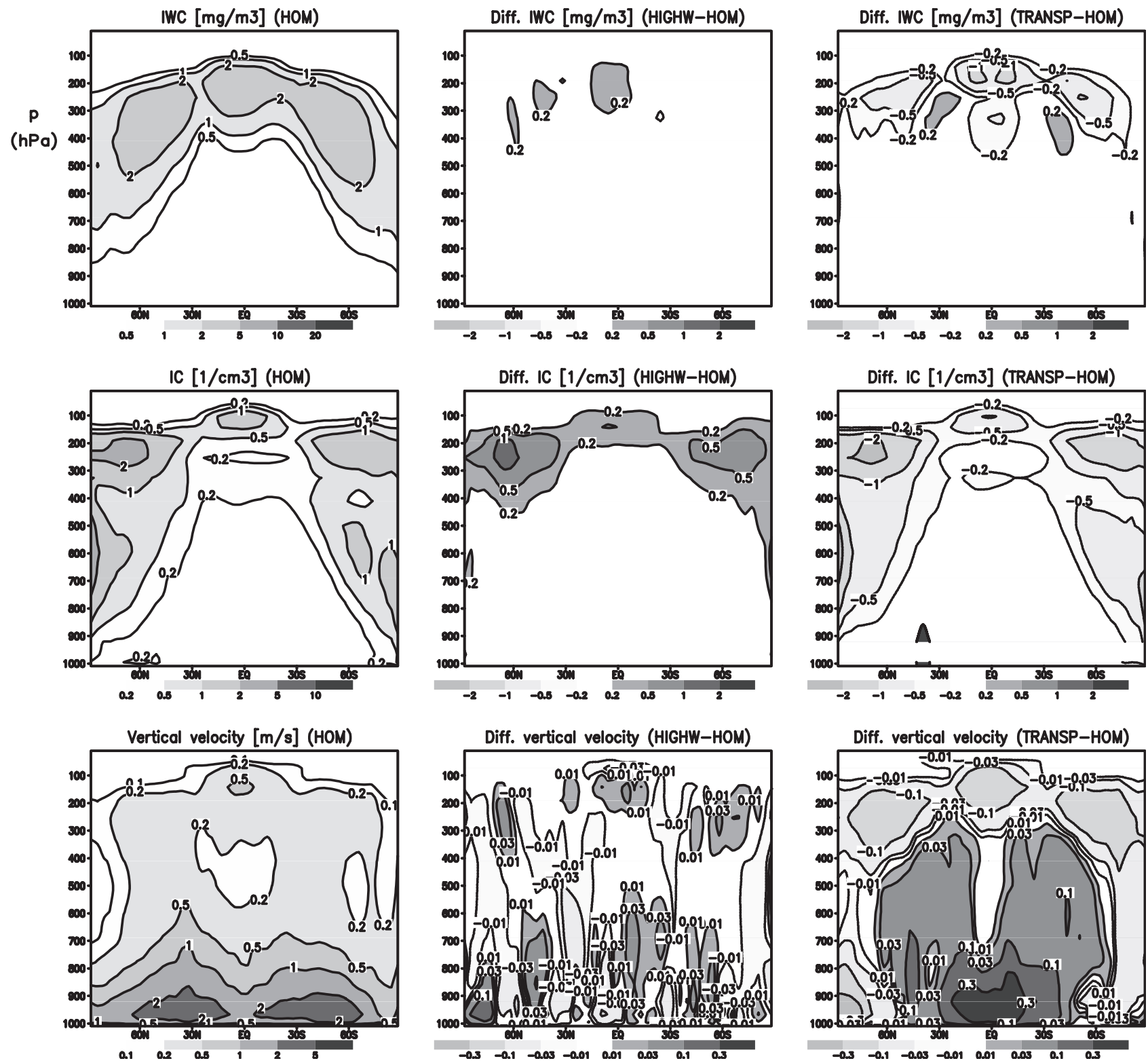

Figure 11. Annual zonal mean latitude versus pressure cross sections of ice water content $\left(\mathrm{mg} \mathrm{m}^{-3}\right)$, ice crystal number concentrations $\left(\mathrm{cm}^{-3}\right)$, and vertical velocity (sum of large scale and subgrid scale) $\left(\mathrm{m} \mathrm{s}^{-1}\right)$ for the simulation HOM and the differences HIGH-W - HOM and TRANSP - HOM.

[34] The differences between HOM and NAT-AP are small. As shown in Figure 13, the number of aerosols has mainly decreased in the lower troposphere (from over $2000 \mathrm{~cm}^{-3}$ to $\sim 300 \mathrm{~cm}^{-3}$ ) but the differences in the cirrus level are much smaller. Less than 10 aerosols $\mathrm{cm}^{-3}$ are mainly found above $200 \mathrm{hPa}$ and at all altitudes over Antarctica in HOM. In NAT-AP the low aerosol region of $<10$ aerosols $\mathrm{cm}^{-3}$ is enlarged and covers the region above $700 \mathrm{hPa}$ at $\mathrm{NH}$ high latitudes, above $500 \mathrm{hPa}$ in the tropics. These low aerosol concentrations are lower than what has been measured from aircraft in remote areas by Schröder et al. [2002] because we do not yet consider episodic eruptive volcanic emissions that reach the stratosphere and that would be another source for upper tropospheric sulfate aerosols. The differences in ice water content are caused by slight differences in meteorology between these simulations. The number of ice crystals has decreased by up to $1 \mathrm{~cm}^{-3}$ in NAT-AP, a change similar to that seen between TRANSP and HOM and between HIGH-W and HOM. This suggests that homogeneous freezing could be limited by the number of hygroscopic aerosols present. However, it could be an artifact because we use a simplified bulk approach but no detailed aerosol microphysics and we are neglecting the stratospheric aerosol source. Moreover, changes in the vertical wind, temperature, and water vapor distributions are as important in controlling the homogeneous nucleation of ice crystals, as explained by Kärcher and Lohmann [2002]. Since the ice water content remains the same in NAT-AP as compared to HOM, there is no change in longwave radiation (Table 2).

[35] The differences in shortwave cloud forcing between NAT$\mathrm{AP}$ and HOM can be attributed to the indirect aerosol effect on water clouds caused by the differences in cloud condensation nuclei. The liquid water clouds in NAT-AP have a smaller liquid water path as their precipitation efficiency is larger (second indirect aerosol effect) and they scatter less solar radiation back to space because the cloud droplets are larger (first indirect aerosol effect). However, as the clear-sky radiation is also affected by the decrease in aerosol number in NAT-AP, the total shortwave aerosol effect is the sum of the changes in clear-sky radiation and shortwave 

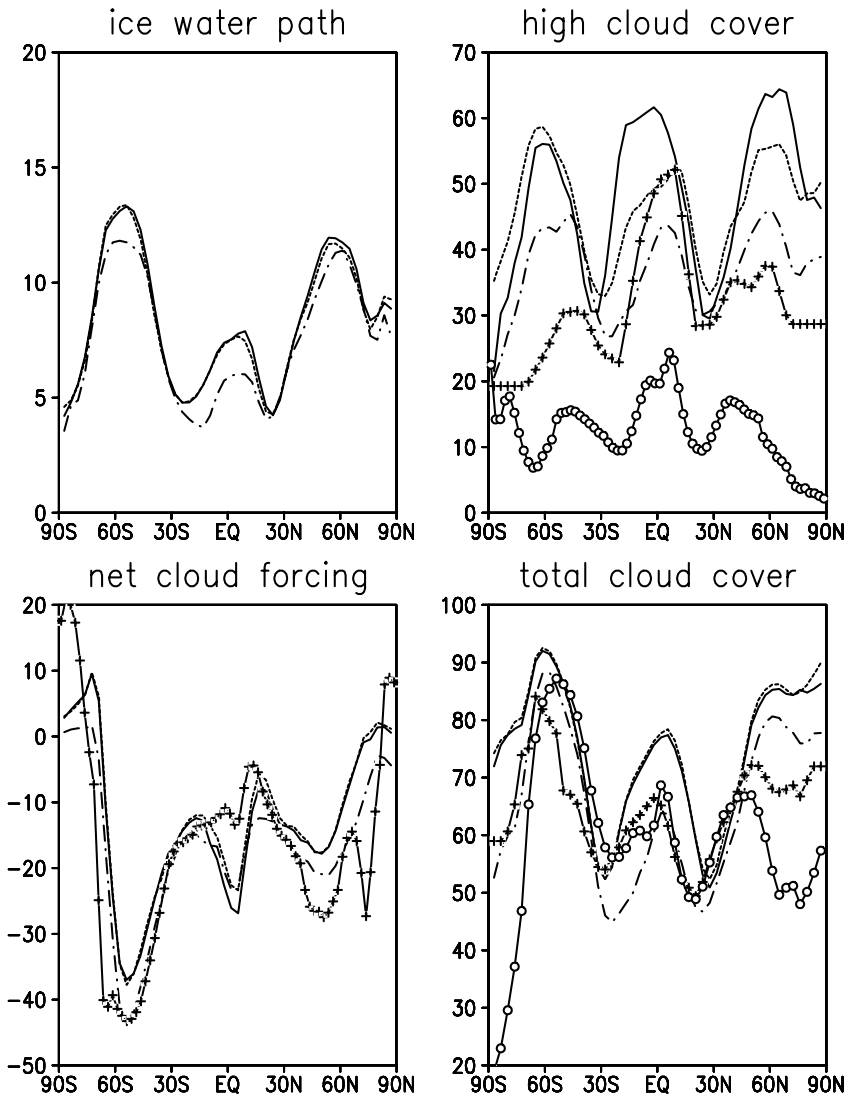

Figure 12. Annual zonal means of ice water path $\left(\mathrm{g} \mathrm{m}^{-2}\right)$, high level cloud cover (\%), total cloud cover (\%), and net cloud forcing $\left(\mathrm{W} \mathrm{m}^{-2}\right.$ ) for the simulations HOM (solid line), HIGH-W (dotted line), TRANSP (dot-dashed line), and observations. Observations for high cloud cover are SAGE data (pluses) and ISCCP (circles); for total cloud cover the data are surface observations by Hahn et al. [1994] (pluses) and ISCCP (circles), and cloud forcing is from ERBE (pluses).

cloud forcing. It amounts to $-1.4 \mathrm{~W} \mathrm{~m}^{-2}$ comparable to the value estimated with a slightly different model setup of Lohmann and Feichter [2001].

[36] The global mean cloud cover, ice water path, and cloud forcings of all the simulations are summarized in Table 2 . The differences in ice water path and cloud cover between the different sensitivity experiments (TRANSP, HIGH-W, and NAT-AP) and HOM are generally smaller than the differences between REF and HOM. The exception is the global mean decrease in shortwave and longwave cloud forcing in TRANSP as compared to HOM.

\subsection{Implications}

[37] Concerns have been raised about the potential of aircraft particle emissions (mainly black carbon (soot) and sulfate aerosols) to modify cirrus cloudiness [Boucher, 1999; Penner et al., 1999, Chapter 3]. Soot and sulfate aerosols are injected directly into the upper troposphere and lowermost stratosphere by cruising subsonic aircraft. The small differences between the simulations HOM and NAT-AP described in section 4.2 imply that sulfate emissions from aviation are unlikely to change the properties of cirrus clouds, even if the initially small (radii $<10 \mathrm{~nm}$ ) sulfate particles would grow to CCN-like sizes $(\sim 80 \mathrm{~nm})$ in the course of their aging in the atmosphere. However, that may not always be the case [Yu and Turco, 1999].

[38] Our results further imply that soot emissions can be expected to exert a larger influence on the formation of cirrus clouds when the soot particles act as heterogeneous freezing nuclei at relative humidities below the homogeneous freezing threshold values. The experimental determination of the freezing potential of aircraft soot particles, which are likely coated with sulfate, organic matter, and water, remains an active area of research [e.g., Kärcher, 2000].

[39] In the simulations we have used a parameterization neglecting a possible effect of aerosol size on the number of ice crystals formed. Nevertheless, we argue that our conclusions about the rather small sensitivity of homogeneous freezing on the number of hygroscopic aerosols present should prove robust for two main reasons. First, Figure 1 shows that a relatively small number of data points contribute to regions in the $\{T, w\}$ space where aerosol size effects on $N_{i}^{\mathrm{HOM}}$ become relevant. Second, detailed microphysical simulations of the cirrus initiation phase with parcel models show that in cases where size effects do play a role, changes of aerosol size parameters lead only to small changes (within a factor of 2 at most) of the calculated values of $N_{i}^{\mathrm{HOM}}$ [Jensen et al., 1998; Kärcher and Lohmann, 2002].

[40] Summarizing the lessons learned from the ECHAM studies, we emphasize that the treatment of subgrid variability as applied to ice crystal nucleation, depositional growth, and cloud cover should be consistent. This is done in statistical cloud schemes [e.g., Smith, 1990; Lohmann et al., 1999b] and will be done in future versions of ECHAM following a scheme developed by Tompkins [2002]. A consistent treatment of nucleation, deposition, and cloud cover in terms of subgrid-scale variability is an essential prerequisite to distinguish changes in cirrus clouds caused by differences in aerosol properties from changes in cirrus clouds caused by differences in meteorology. Moreover, a detailed aerosol microphysics scheme is necessary to simulate the actual number of hygroscopic particles in cirrus levels.

\section{Summary and Outlook}

[41] In this paper, we introduced the novel parameterization for homogeneous ice nucleation developed by Kärcher and Lohmann [2002] in the ECHAM GCM and performed the first interactive simulations of cirrus clouds in a global climate model. By means of sensitivity studies, we identified the most important processes affecting cloud formation in such an approach.

[42] To apply this parameterization, we had to allow supersaturations with respect to ice in the simulations. Therefore we abandoned the saturation adjustment scheme and introduced the deposition parameterization by Levkov et al. [1992] that is used in the mesoscale cloud model GESIMA. This parameterization explicitly depends on the saturation ratio and the number of ice crystals being present. The number of ice crystals is obtained from the Kärcher and Lohmann [2002] parameterization for homogeneous freezing below $-35^{\circ} \mathrm{C}$ and from the Meyers et al. [1992] parameterization for heterogeneous nucleation above $-35^{\circ} \mathrm{C}$. The main results of our study are as follows:

1. The formation and frequency of occurrence of cirrus clouds formed by homogeneous freezing of supercooled liquid aerosol particles are controlled by the vertical velocity and the temperature in the grid box and in some cases by the number of hygroscopic aerosols. The number of cirrus ice crystals formed in this way increases with increasing vertical velocity and decreasing temperature.

2. Assuming homogeneous freezing for all simulated types of particles below $-35^{\circ} \mathrm{C}$ in the upper troposphere, anthropogenic changes of the hygroscopic aerosol concentration (e.g., of the abundance of sulfates and carbonaceous aerosols) do not result in a significant impact on cirrus cloud radiative properties but may determine ice crystal number concentrations in cirrus. The latter may be an artifact because we use a simplified bulk approach but no detailed aerosol microphysics. Thus emissions of Aitken mode sulfate particles from aviation are unlikely to change the properties of cirrus clouds. Aircraft soot emissions will be important if the 

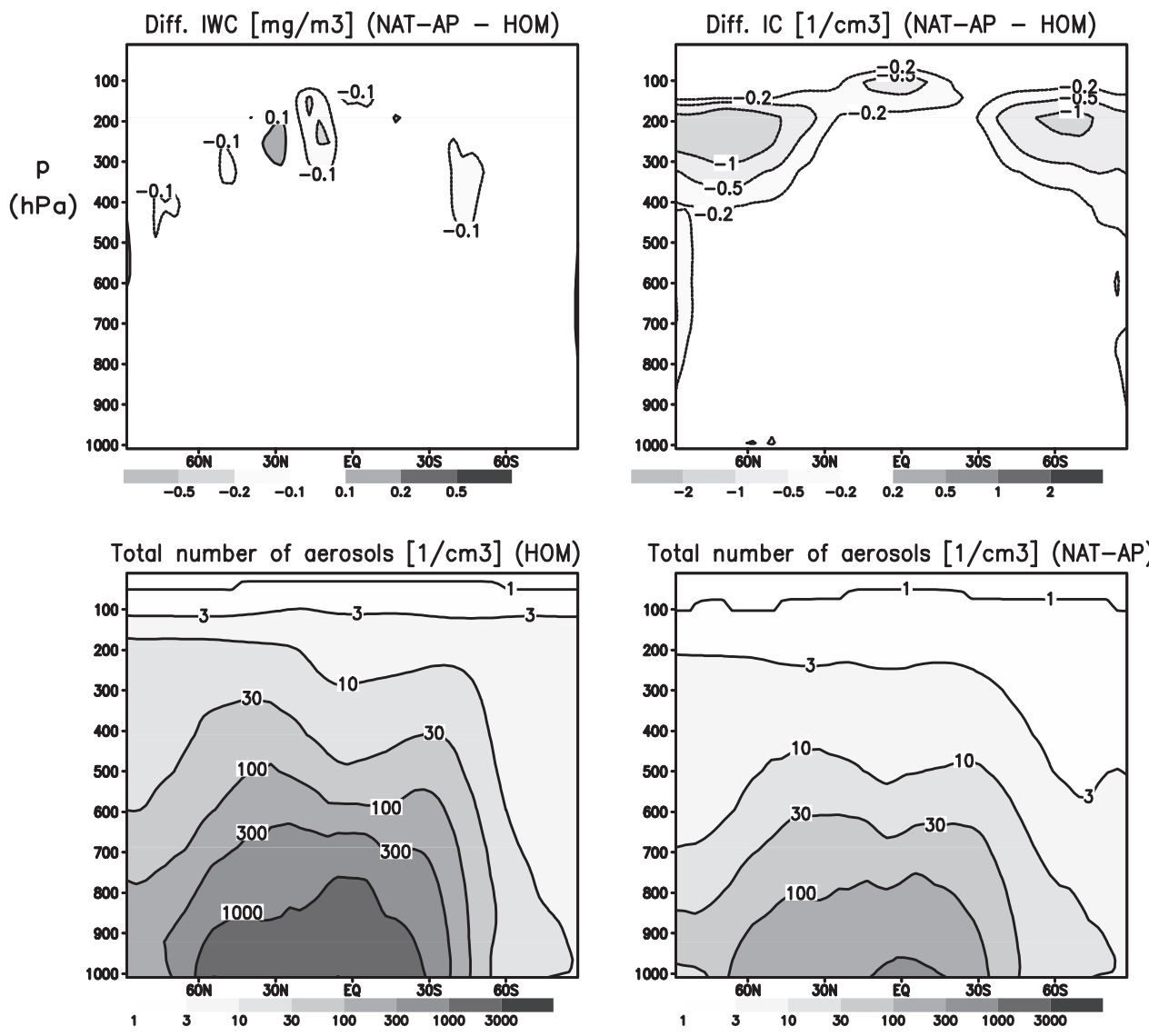

Figure 13. Annual zonal mean latitude versus pressure cross sections of the difference in ice water content $\left(\mathrm{mg} \mathrm{m}^{-3}\right)$ and ice crystal number concentrations $\left(\mathrm{cm}^{-3}\right)$ between the simulations HOM and NAT-AP and aerosol number concentration $\left(\mathrm{cm}^{-3}\right)$ for HOM and NAT-AP.

soot particles nucleate more efficiently than by homogeneous freezing.

3. The comparison with data taken on commercial aircraft (MOZAIC) showed that ECHAM reproduces the frequency distribution of supersaturation with respect to ice in cloud-free regions well especially if high values of the subgrid-scale vertical velocity are assumed. On the other hand, the higher frequency of occurrence of high supersaturations in the model may point to heterogeneous freezing as a missing mechanism for ice formation in the upper troposphere.

[43] As other GCMs, ECHAM only simulates one mean value of the vertical velocity in each grid box. However, in reality, many different values of the vertical velocity occur in a grid box, suggesting that one should integrate over appropriate probability density functions to obtain the nucleation rates. The same holds for subgrid-scale fluctuations of temperature and relative humidity. There is also a pending inconsistency between simulated cloud cover and cloud microphysics. To address these aspects is beyond the scope of this paper but will be considered in future work.

[44] Furthermore, as most GCMs, ECHAM suffers from a cold bias in the polar upper troposphere and the lower stratosphere in both hemispheres [Roeckner et al., 1996]. The cold bias is particularly large over the respective summer pole (up to $-15 \mathrm{~K}$ over Antarctica). This feature is typical for GCMs and turns out to be insensitive to model formulation [Boer et al., 1992]. Increasing the numbers of vertical levels near the tropopause reduces the bias only slightly [Land et al., 1999]. This temperature error leads to errors in the water vapor and relative humidity distributions. Thus any improvement in the temperature bias will result in a better agreement of simulated high level cloud cover.
[45] In a next step, we will generalize our analytic parameterization of homogeneous freezing to include aerosol size effects on cloud formation. Incorporating the refined parameterization into ECHAM will enable us to reassess our results using a more realistic description of cirrus formation as well as to investigate the effects of enhanced sulfate aerosol levels caused by strong volcanic eruptions on the properties of high ice clouds [Sassen, 1992]. Finally, the inclusion of heterogeneous freezing processes in future work will enable us to assess the role of different types of freezing particles as well as to better judge about the relative importance of subgrid-scale fluctuations and differences between advective transport schemes on cloud formation.

[46] Acknowledgments. Ulrike Lohmann is grateful for support from the National Science and Engineering Research Council of Canada and the Canadian Foundation for Climate and Atmospheric Science. She also thanks the Deutsches Klimarechenzentrum for computing time. This work contributes to the HGF/BMBF project "Particles and Cirrus Clouds" (PAZI). We thank the anonymous reviewers for helpful comments and suggestions.

\section{References}

Ackerman, T. P., K. N. Liou, F. P. J. Valero, and L. Pfister, Heating rates in tropical anvils, J. Atmos. Sci., 45, 1606-1623, 1988.

Boer, G. J., et al., Some results from an intercomparison of the climates simulated by 14 atmospheric general circulation models, J. Geophys. Res., 97, 12,771-12,786, 1992.

Boucher, O., Air traffic may increase cirrus cloudiness, Nature, 397, 3031, 1999. 
Chen, Y., P. J. DeMott, S. M. Kreidenweis, D. C. Rogers, and D. E. Sherman, Ice formation by sulfate and sulfuric acid aerosol particles under upper tropospheric conditions, J. Atmos. Sci., 57, 3752-3766, 2000

Cziczo, D. J., and J. P. D. Abbatt, Deliquescence, efflorescence, and supercooling of ammonium sulfate aerosols at low temperature: Implications for cirrus cloud formation and aerosol phase in the atmosphere, J. Geophys. Res., 104, 13,781-13,790, 1999.

Del Genio, A. D., M. S. Yao, W. Kovari, and K. K. W. Lo, A prognostic cloud water parameterization for global climate models, J. Clim., 9, 270304, 1996.

Fowler, L. D., D. A. Randall, and S. A. Rutledge, Liquid and ice cloud microphysics in the csu general circulation model, part I, Model description and simulated microphysical processes, J. Clim., 9, 489-529, 1996.

Gierens, K., U. Schumann, M. Helten, H. Smit, and A. Marenco, A distribution law for relative humidity in the upper troposphere and lower stratosphere derived from three years of MOZAIC measurements, Ann. Geophys., 17, 1218-1226, 1999.

Hahn, C. J., S. G. Warren, and J. London, Climatological data for clouds over the globe from surface observations, 1982-1991: The total cloud edition, Tech. Rep. ORNL/CDIAC-72 NDP-026A, Oak Ridge Natl. Lab., Oak Ridge, Tenn., 1994.

Hartmann, D. L., Radiative effects of clouds on Earth's climate, in AerosolCloud-Climate Interactions, Int. Geophys. Ser., vol. 54, edited by P. V. Hobbs, pp. 151-173, Academic, San Diego, Calif., 1993.

Hess, M., P. Koepke, and I. Schult, Optical properties of aerosols and clouds: The software package OPAC, Bull. Am. Meteorol. Soc., 79, $831-844,1998$.

Jensen, E. J., et al., Ice nucleation processes in upper tropospheric waveclouds observed during SUCCESS, Geophys. Res. Lett, 25, 1363-1366, 1998.

Kärcher, B., Contrails: Observations, formation mechanisms, atmospheric impacts, uncertainties, DLR Tech. Rep. 2000-01, 47 pp., DLR, Oberpfaffenhofen, Germany, 2000.

Kärcher, B., and U. Lohmann, A parameterization of cirrus cloud formation: Homogeneous freezing of supercooled aerosols, J. Geophys. Res., 107(D1), 10.1029/2001JD000470, 2002.

Koop, T., B. Luo, A. Tsias, and T. Peter, Water activity as the determinant for homogeneous ice nucleation in aqueous solutions, Nature, 406, 611614, 2000.

Land, C., M. Ponater, R. Sausen, and E. Roeckner, The ECHAM4.L39 (DLR) atmosphere GCM-Technical description and model climatology, DLR Tech. Rep. 31, 45 pp., DLR, Oberpfaffenhofen, Germany, 1999.

Levkov, L., B. Rockel, H. Kapitza, and E. Raschke, 3D mesoscale numerical studies of cirrus and stratus clouds by their time and space evolution, Beitr. Phys. Atmos., 65, 35-58, 1992.

Liao, X., W. B. Rossow, and D. Rind, Comparison between SAGE II and ISCCP high-level clouds, 1, Global and zonal mean cloud amounts, $J$. Geophys. Res., 100, 1121-1135, 1995.

Lin, H., and W. R. Leaitch, Development of an in-cloud aerosol activation parameterization for climate modelling, in Proceedings of the WMO Workshop on Measurement of Cloud Properties for Forecasts of Weather, Air Quality and Climate, pp. 328-335, World Meteorol. Organ., Geneva, 1997.

Liou, K.-N., Influence of cirrus clouds on weather and climate processes: A global perspective, Mon. Weather Rev., 114, 1167-1199, 1986.

Lohmann, U., Possible aerosol effects on ice clouds via contact nucleation, J. Atmos. Sci., 59, 647-656, 2002.

Lohmann, U., and J. Feichter, Can the direct and semi-direct aerosol effect compete with the indirect effect on a global scale?, Geophys. Res. Lett., 28, 159-161, 2001

Lohmann, U., and E. Roeckner, Design and performance of a new cloud microphysics scheme developed for the ECHAM general circulation model, Clim. Dyn., 12, 557-572, 1996.

Lohmann, U., J. Feichter, C. C. Chuang, and J. E. Penner, Predicting the number of cloud droplets in the ECHAM GCM, J. Geophys. Res., 104, 9169-9198, 1999a.
Lohmann, U., N. McFarlane, L. Levkov, K. Abdella, and F. Albers, Comparing different cloud schemes of a single column model by using mesoscale forcing and nudging technique, J. Clim., 12, 438-461, 1999b.

Mace, G. G., E. E. Clothiaux, and T. P. Ackerman, The composite characteristics of cirrus clouds: Bulk properties revealed by one year of continuous cloud radar data, J. Clim., 14, 2185-2203, 2001.

Meyers, M. P., P. J. DeMott, and W. R. Cotton, New primary ice-nucleation parameterization in an explicit cloud model, J. Appl. Meteorol., 31, $708-$ $721,1992$.

Ou, S.-C., and K.-N. Liou, Ice microphysics and climatic temperature feedback, Atmos. Res., 35, 127-138, 1995.

Penner, J. E., D. H. Lister, D. J. Griggs, D. J. Dokken, and M. McFarland (Eds.), Aviation and the Global Atmosphere: Intergovernmental Panel on Climate Change, 373 pp., Cambridge Univ. Press, New York, 1999.

Pruppacher, H. R., and J. D. Klett, Microphysics of Clouds and Precipitation, Kluwer Acad., Norwell, Mass., 1997.

Rasch, P., and M. Lawrence, Recent development in transport methods at NCAR, in MPI Workshop on Conservative Transport Schemes, edited by B. Machenhauer, Rep. 265, pp. 65-75, Max Planck Inst. for Meteorol., Hamburg, Germany, 1998.

Rasch, P. J., and D. L. Williamson, Computational aspects of moisture transport in global models of the atmosphere, Q. J. R. Meteorol. Soc., 116, 1071-1090, 1990.

Roeckner, E., et al., The atmospheric general circulation model ECHAM4: Model description and simulation of the present day climate, Tech. Rep. 218, Max Planck Inst. for Meteorol., Hamburg, Germany, 1996.

Rossow, W. B., and R. A. Schiffer, Advances in understanding clouds from ISCCP, Bull. Am. Meteorol. Soc., 80, 2261-2287, 1999.

Rotstayn, L. D., On the "tuning" of autoconversion parameterizations in climate models, J. Geophys. Res., 105, 15,495-15,508, 2000.

Sassen, K., Evidence for liquid-phase cirrus cloud formation from volcanic aerosols: Climate implications, Science, 257, 1357-1369, 1992.

Schröder, F., B. Kärcher, M. Fiebig, and A. Petzold, Aerosol sources and transformation processes in the free troposphere and tropopause region at northern midlatitudes, J. Geophys. Res., 107(DX), 10.1029/ 2001JD000194, in press, 2002.

Smith, R. N., A scheme for predicting layer clouds and their water content in a general circulation model, Q. J. R. Meteorol. Soc, 116, 435-460, 1990.

Sundqvist, H., E. Berge, and J. E. Kristiansson, Condensation and cloud parameterization studies with a mesoscale numerical weather prediction model, Mon. Weather Rev., 117, 1641-1657, 1989.

Tompkins, A. M., A prognostic parameterization for the subgrid-scale variability of water vapor and clouds in large-scale models and its use to diagnose cloud cover, J. Atmos. Sci., in press, 2002.

Wang, P.-H., P. Minnis, M. P. McCormick, G. S. Kent, and K. M. Skeens, A 6-year climatology of cloud occurrence frequency from Stratospheric Aerosol and Gas Experiment II observations (1985-1990), J. Geophys. Res., 101, 29,407-29,429, 1996.

Wilson, D. R., and S. P. Ballard, A microphysically based precipitation scheme for the uk meteorological office unified model, Q. J. R. Meteorol. Soc., 125, 1607-1636, 1999.

Wylie, D. P., and W. P. Menzel, Eight years of high cloud statistics using HIRS, J. Clim., 12, 170-184, 1999.

Yu, F., and R. P. Turco, Evolution of aircraft-generated volatile particles in the far wake regime: Potential contributions to ambient CCN/IN, Geophys. Res. Lett., 26, 1703-1706, 1999.

B. Kärcher, DLR Institut für Physik der Atmosphäre, D-82234 Wessling, Germany.

U. Lohmann, Department of Physics and Atmospheric Science, Dalhousie University, Halifax, Nova Scotia, Canada B3H 3J5. (Ulrike. Lohmann@) Dal.Ca) 

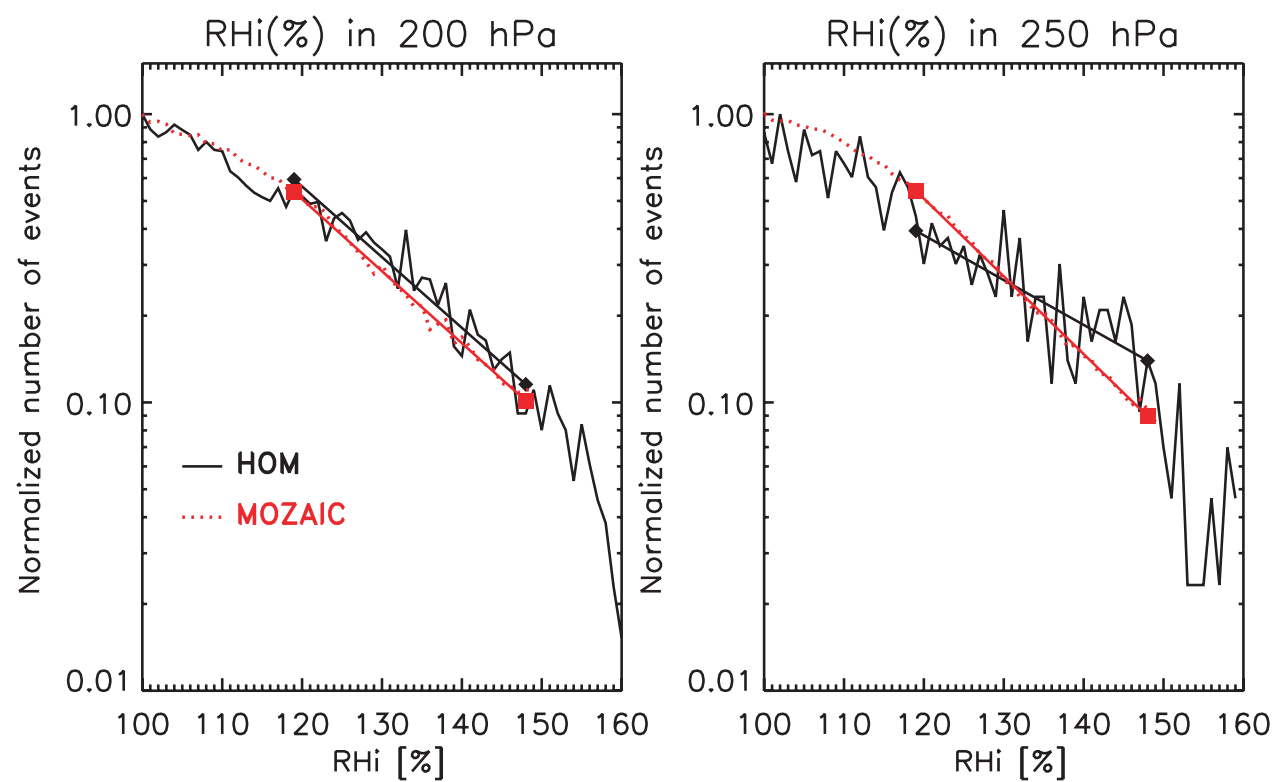

Figure 2. Normalized frequency distribution of relative humidity with respect to ice in two layers centered around 200 and $250 \mathrm{hPa}$ for cloud-free conditions from MOZAIC observations and simulation HOM. The solid lines refer to the slopes summarized in Table 1.
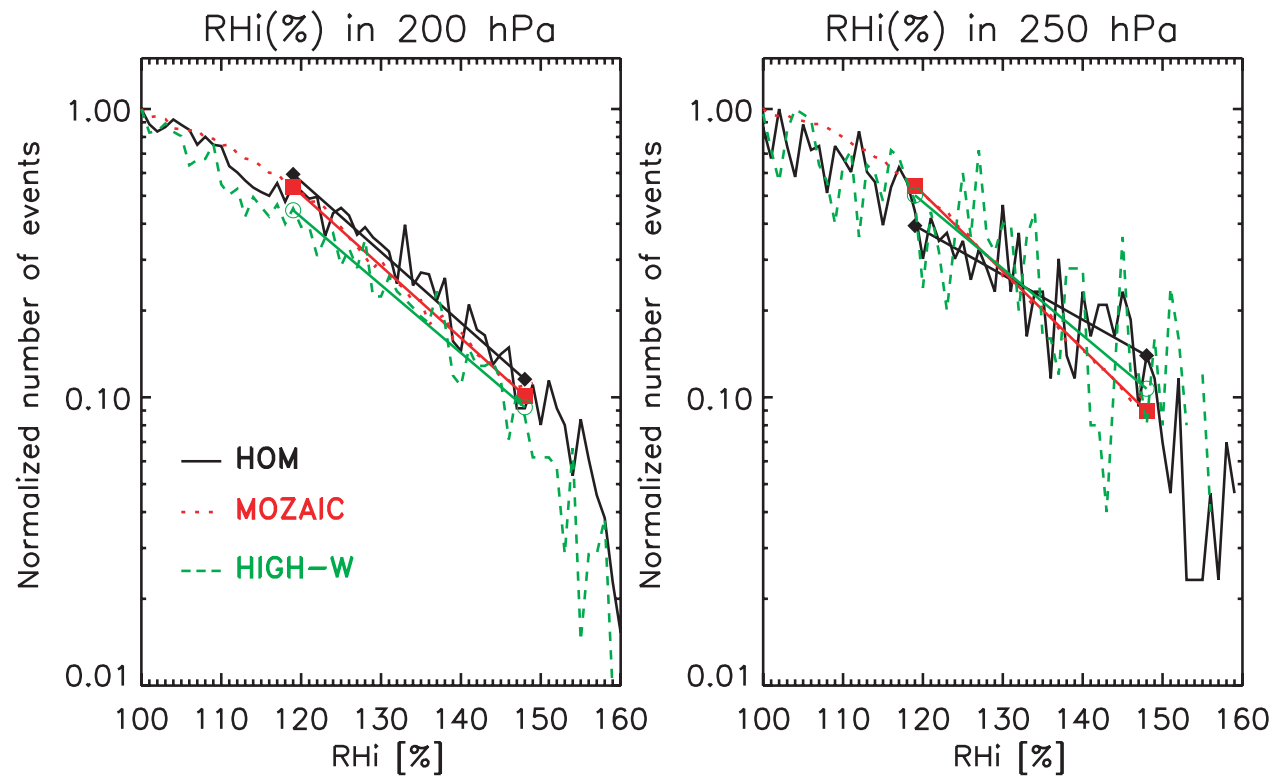

Figure 8. Normalized frequency distribution of relative humidity with respect to ice in two layers centered around 200 and $250 \mathrm{hPa}$ for cloud-free conditions from MOZAIC observations and the simulations HOM and HIGH-W. 

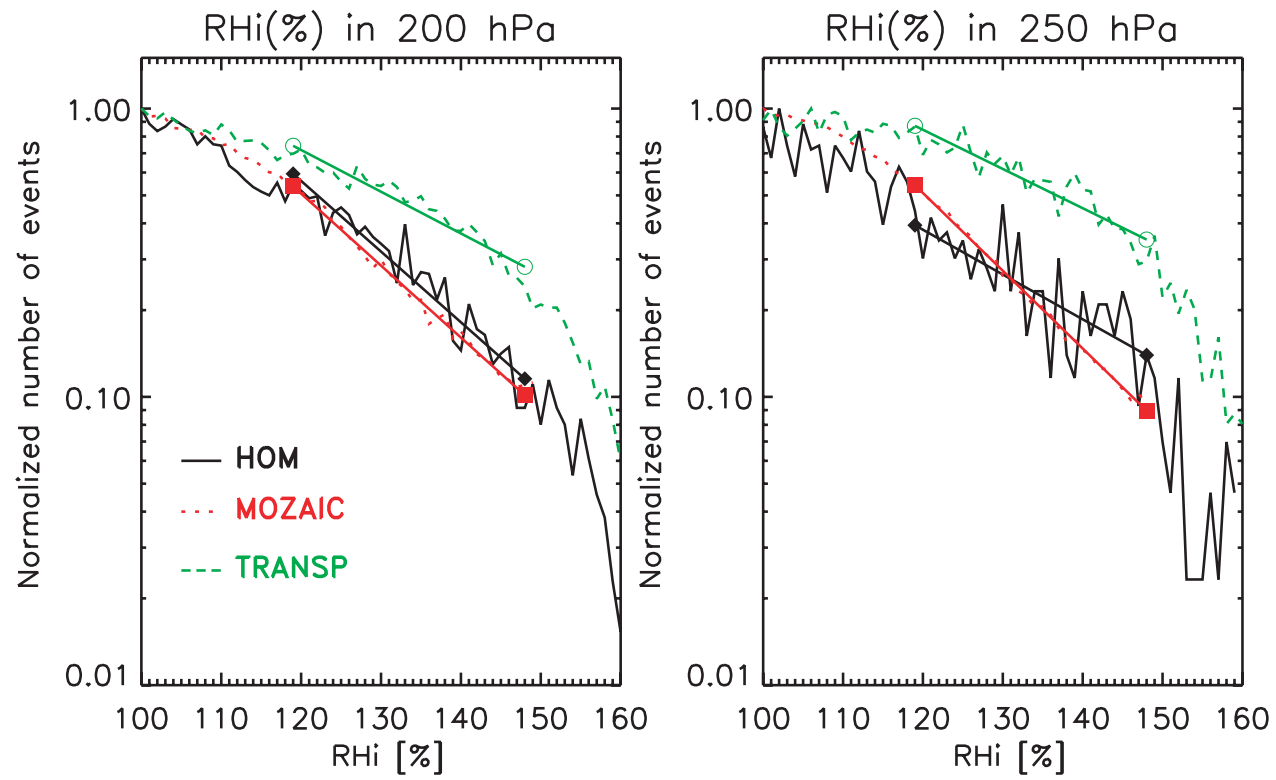

Figure 9. Normalized frequency distribution of relative humidity with respect to ice in two layers centered around 200 and $250 \mathrm{hPa}$ for cloud-free conditions from MOZAIC observations and the simulations HOM and TRANSP. 